\title{
Novel Design of Microstrip Antenna with Improved Bandwidth
}

\author{
Km. Kamakshi, Ashish Singh, Mohammad Aneesh, and J. A. Ansari \\ Department of Electronics and Communication, University of Allahabad, Allahabad 211002, India \\ Correspondence should be addressed to Km. Kamakshi; kamakshi.kumar21@gmail.com
}

Received 1 August 2014; Revised 23 September 2014; Accepted 24 September 2014; Published 2 October 2014

Academic Editor: Paolo Colantonio

Copyright (C) $2014 \mathrm{Km}$. Kamakshi et al. This is an open access article distributed under the Creative Commons Attribution License, which permits unrestricted use, distribution, and reproduction in any medium, provided the original work is properly cited.

\begin{abstract}
A novel design of broadband patch antenna is presented in this paper. The broadband property of the proposed antenna is achieved by choosing a proper selection of dimensions and positions of slot and notch on the radiating patch. The bandwidth of the proposed antenna is found to be $30.5 \%$ with operating frequency band from $1.56 \mathrm{GHz}$ to $2.12 \mathrm{GHz}$. Antenna characteristics are observed for different inclination angles " $\alpha$ " and its effect on bandwidths is also reported. The maximum gain of the antenna is found to be $9.86 \mathrm{dBi}$ and it achieves broadside radiation pattern in the direction of maximum radiation over the operating band. The proposed antenna structure is simulated, fabricated, and tested for obtaining the desired performance. The simulated results are verified with experimental results which are in good agreement.
\end{abstract}

\section{Introduction}

In last few years, microstrip patch antenna attracted considerable amount of attention of researchers due to demand of its large variety of applications in different fields such as radar, aircraft, missiles, satellite communications, biomedical telemetry, remote sensing, and different other wireless applications. However, the main limitation of the conventional microstrip patch antenna is narrow bandwidth that restricts its applications [1]. Due to this reason, serious efforts started among the scientists, researchers, and designers to improve the bandwidth of the patch antenna. The bandwidth improvement is achieved by loading a different shape and size of slots and notches on the patch or in the ground plane. There are different other bandwidth enhancement techniques that are also available, but this technique is simple in design and easy in loading and improving bandwidth without increasing the volume of the structures. Therefore, a number of papers have been reported by the researchers for wireless applications such as U-slot loaded rectangular microstrip antenna, Lshaped slot loaded rectangular microstrip antenna, stepped U-slot loaded rectangular microstrip antenna, and half stepped U-slot loaded compact shorted square microstrip antenna, and edge center-shorted square microstrip antenna with stepped slot achieved bandwidth of $17.4 \%, 14.6 \%, 14.3 \%$, $23.5 \%$, and $17.3 \%$, respectively [2], compact broadband slotted rectangular microstrip antenna reported $26.7 \%$ bandwidth [3], W-shaped patch antenna presented $36.7 \%$ bandwidth [4], M-slot folded patch antenna provided $21.17 \%$ bandwidth [5], E-H shaped microstrip patch antenna covered frequency range from $1.76 \mathrm{GHz}$ to $2.38 \mathrm{GHz}$ which is equal to $30 \%$ bandwidth [6], and V-slots corner notch loaded microstrip patch antenna employed 51\% bandwidth [7]. Further, several other radiating structures have been also reported for the bandwidth enhancement of microstrip antenna: star-shaped patch antenna covered frequency range from 4.0 to $8.8 \mathrm{GHz}$ [8]; C-shaped, E-shaped, and U-slot microstrip patch antennas obtained bandwidth of $0.84 \%, 24 \%$, and $25 \%$, respectively [9], plus-shaped and cross-shaped slot loaded patch antenna achieved bandwidth of $53 \%$ and $6.49 \%$, respectively [10, 11]; multi-slotted patch antenna reported $27.62 \%$ bandwidth [12]; and slot-coupled multilayer radiating element for synthetic aperture radar application provided bandwidth of $16 \%$ bandwidth [13].

This paper is highly motivated from the above reported papers and an antenna radiating structure has been proposed for achieving the improved bandwidth that can be utilized for wireless applications. Most of the reported papers in the literature have achieved gain below $9.0 \mathrm{dBi}$, whereas the proposed design achieved maximum gain of $9.86 \mathrm{dBi}$ with $30.5 \%$ of bandwidth. The performance of proposed antenna is also studied as a function of inclination angle " $\alpha$." The proposed 


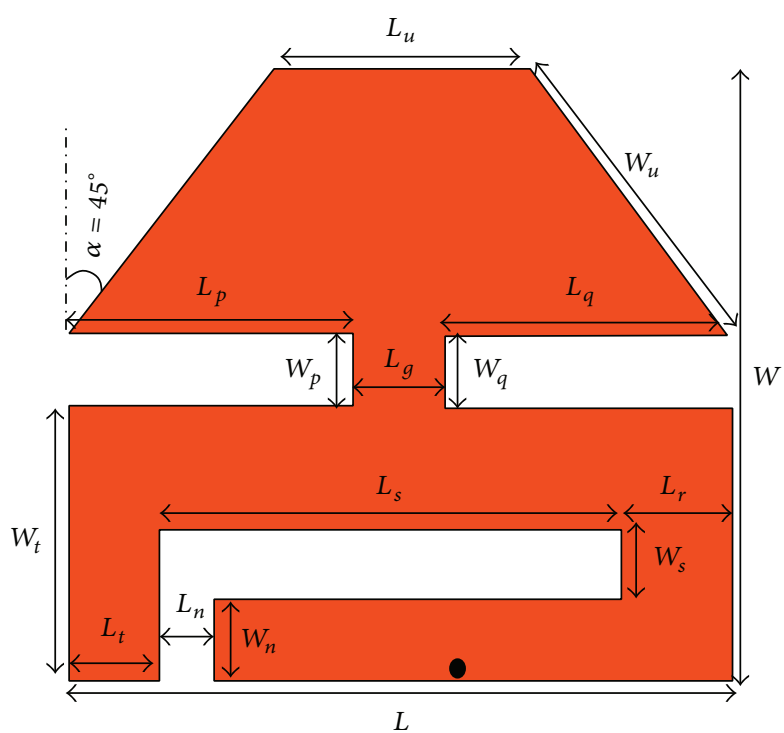

(a)

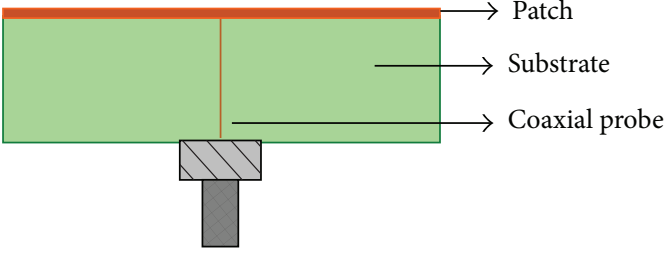

(b)

FIGURE 1: Structure of proposed microstrip patch antenna: (a) top view and (b) side view.

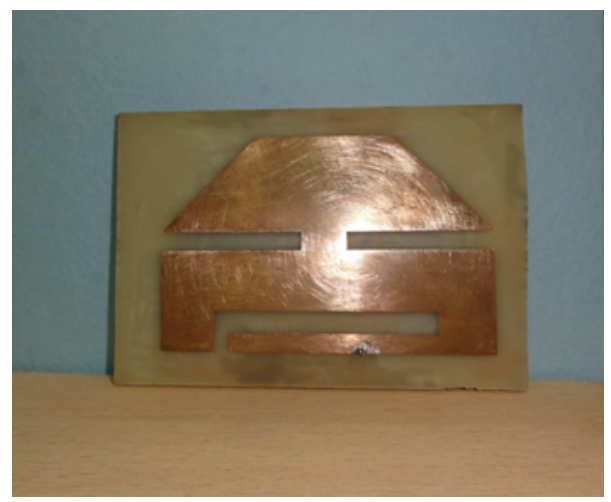

FIgURE 2: Photograph of the fabricated antenna.

design is optimized using IE3D simulation software which is based on method of moment. The antenna is simulated, fabricated, and tested for obtaining the desired performance. The simulated results are verified with experimental ones that prove the accuracy of the designed antenna. The details of proposed antenna are given in the following sections.

\section{Antenna Configuration and Analysis}

The proposed antenna of dimension $(L \times W)$ is fabricated on FR4 substrate with dielectric constant of 4.4. The antenna consist of a rectangular patch loaded with three notches and one slot of dimensions $\left(L_{n} \times W_{n}\right),\left(L_{P} \times W_{P}\right),\left(L_{q} \times W_{q}\right)$, and $\left(L_{S} \times W_{S}\right)$, respectively. The patch is excited via coaxial feed. The geometry of the patch antenna is shown in Figure 1 and related parameter values are presented in Table 1 . The photograph of the fabricated antenna is shown in Figure 2.

The current distribution of the proposed antenna at centre frequency is shown in Figure 3. From Figure 3, it is observed that the maximum current strength is obtained in the upper portion (tilted portion) of the radiating patch which follows longer path in comparison to lower portion. There are four directions of current flowing on the radiating patch which are responsible for the generation of lower and higher order of the TM modes. These nearly excited modes are combined and give wider bandwidth.

\section{Results and Discussion}

The proposed broadband antenna has been successfully implemented and tested for its desired performance. The simulated results are obtained by method of moment-based simulator, IE3D [14], and its results are experimentally verified by network analyzer. The detailed information about designed antenna characteristics is discussed in this section.

Figure 4 shows the frequency versus reflection coefficient of the proposed antenna. Simulated result of the designed antenna shows four resonating modes at $1.59 \mathrm{GHz}, 1.71 \mathrm{GHz}$, 


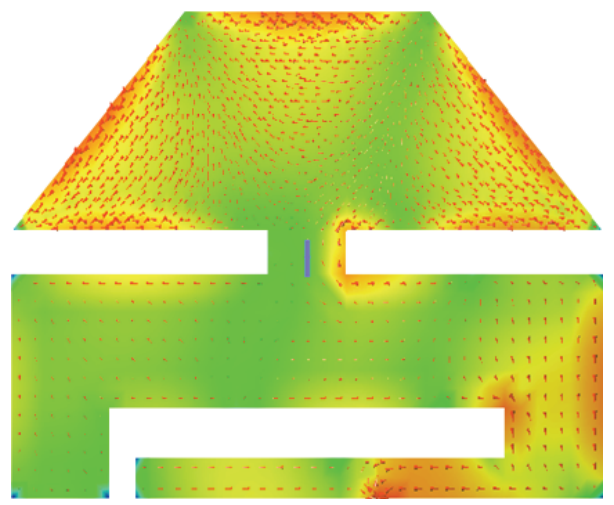

FIGURE 3: Simulated current distribution of the proposed antenna at centre frequency.

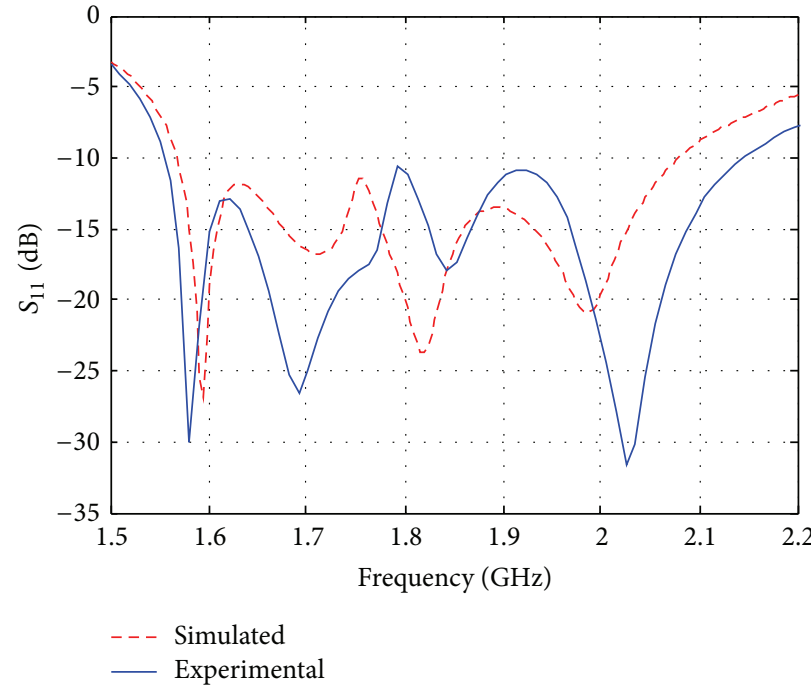

FIGURE 4: Plot of reflection coefficient with frequency for proposed antenna.

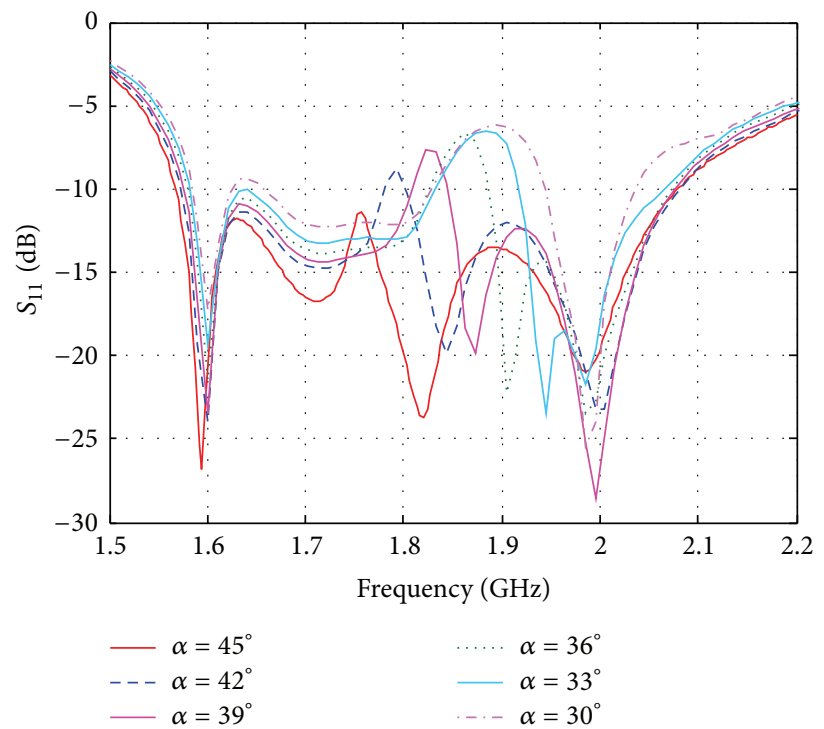

FIGURE 5: The variation of reflection coefficient with frequency for the different value of inclination angle " $\alpha$." 


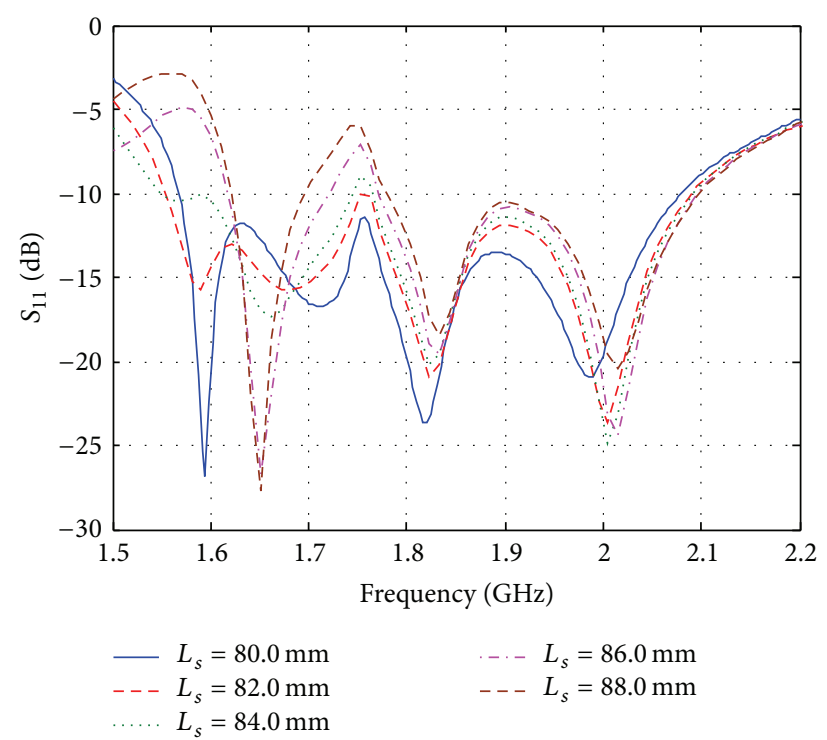

FIGURE 6: The variation of reflection coefficient with frequency for the different value of slot length " $L_{S}$ ".

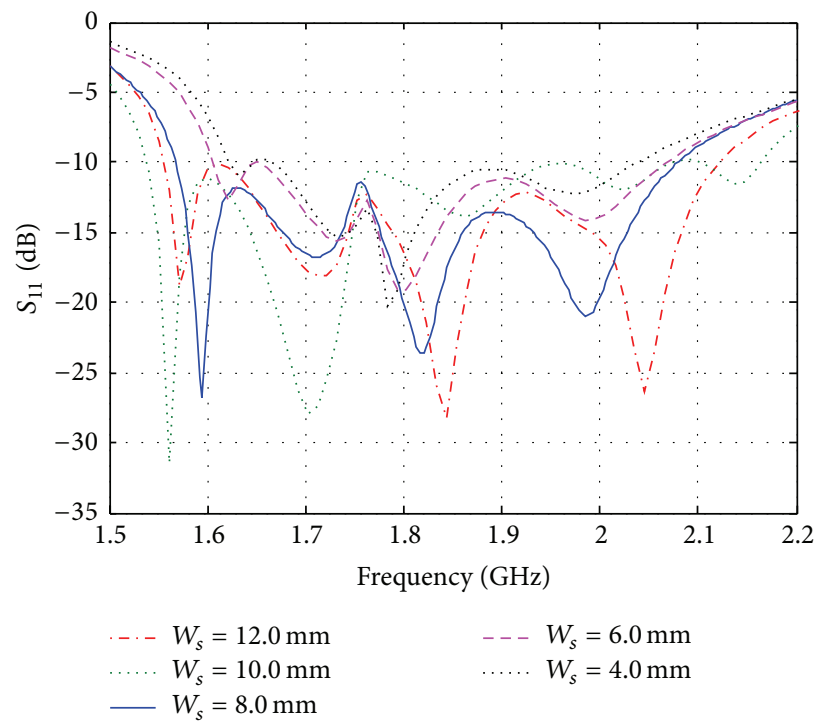

FIGURE 7: The variation of reflection coefficient with frequency for the different value of slot width " $W_{S}$."

$1.81 \mathrm{GHz}$, and $1.98 \mathrm{GHz}$ which combine to give broader bandwidth of $29.6 \%$, whereas the experimental results show that the four close resonating modes appear at $1.58 \mathrm{GHz}$, $1.69 \mathrm{GHz}, 1.84 \mathrm{GHz}$, and $2.01 \mathrm{GHz}$, respectively, gives wider bandwidth of $30.5 \%$. It is found that the simulated result is in acceptable agreement with the experimental result. Small discrepancy occurred between them due to fabrication losses, whereas simulated results are taken in ideal conditions.

Figure 5 shows the effect of inclination angle or tilt angle " $\alpha$ " on the antenna performance. The frequency versus reflection coefficient curve is plotted for different values of inclination angle. With decreasing the values of " $\alpha$ " the third resonance disappears and antenna characteristic changes from broadband to dual band. The corresponding bandwidth of the inclination angle also decreases with decreasing the value of tilt angle. Therefore, it is observed that inclination angle plays a crucial role in controlling the resonating frequencies as well as bandwidth of the antenna.

Figure 6 shows the effect of slot lengths " $L_{S}$ " on the antenna performance while all other parameters are constant. The slot length of the antenna varies from $80 \mathrm{~mm}$ to $88 \mathrm{~mm}$ and its effects are studied on the antenna characteristics. From Figure 6, it is observed that on increasing the value of slot length resonating frequencies are shifted and their corresponding reflection coefficients are degraded and after the value of slot length " $L_{S}=84.0 \mathrm{~mm}$ " the second resonance totally disappears and antenna characteristics are changed from broadband to dual band with wider bandwidth.

Figure 7 shows the variation of the reflection coefficient on changing the value of " $W_{S}$ " (width of the slot). From 


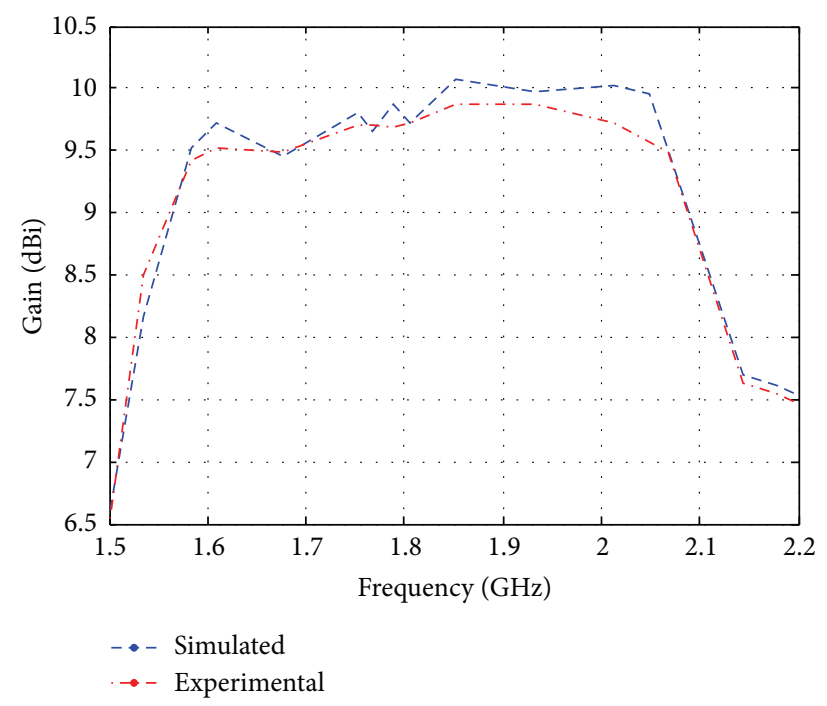

FIGURE 8: Gain of the antenna at various frequencies of operating band.

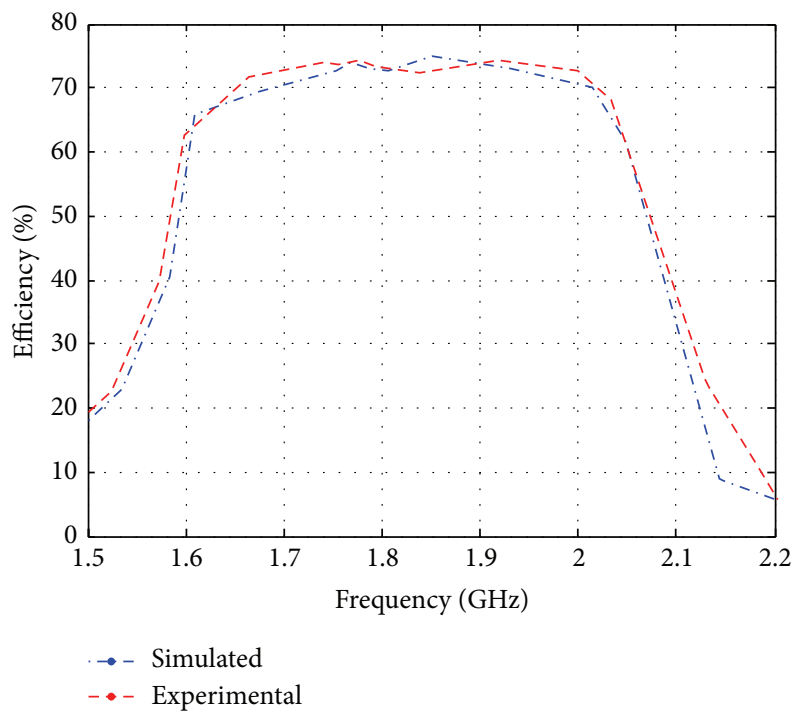

FIGURE 9: Efficiency of the antenna at various frequencies of operating band.

Figure 7, it is observed that on decreasing the slot width from $8.0 \mathrm{~mm}$ to $4.0 \mathrm{~mm}$ corresponding bandwidth of the antenna decreases and decreases the value of reflection coefficients. On the other hand, when width of the slot increases from $8.0 \mathrm{~mm}$ to $12.0 \mathrm{~mm}$ the corresponding bandwidth increases. The slot width of $12.0 \mathrm{~mm}$ has not been used for designing because other values of antenna characteristics are degraded.

The simulated gain and measured gain of the proposed antenna at various frequencies are shown in Figure 8. From Figure 8 , it is observed that the gain varies from $9.2 \mathrm{dBi}$ to $9.0 \mathrm{dBi}$ over an operating frequency range from $1.56 \mathrm{GHz}$ to $2.12 \mathrm{GHz}$. The maximum simulated and measured gain are found to be $10.1 \mathrm{dBi}$ (at $1.86 \mathrm{GHz}$ ) and $9.86 \mathrm{dBi}$ (at $1.84 \mathrm{GHz}$ ), respectively. The total efficiency of the proposed antenna is shown in Figure 9. The maximum simulated and measured efficiency of the antenna are $75.0 \%$ and $74.5 \%$, respectively.
The small discrepancy is observed between simulated and measured results and this is due to design tolerance of the antenna. These characteristics of an antenna satisfied the requirement of some wireless communication devices.

The E-plane and $\mathrm{H}$-plane radiation pattern at the centre frequency are shown in Figure 10. It is found that the antenna radiates maximum power in broadside direction within the operating band and the $3 \mathrm{~dB}$ beamwidth for E-plane is calculated to be $55^{\circ}$, whereas for $\mathrm{H}$-plane it is $45^{\circ}$. It means that, at $1.84 \mathrm{GHz}$, antenna radiates most of the power at these specified beam widths.

\section{Conclusion}

A broadband patch antenna with improved bandwidth has been discussed and presented successfully. The designed 


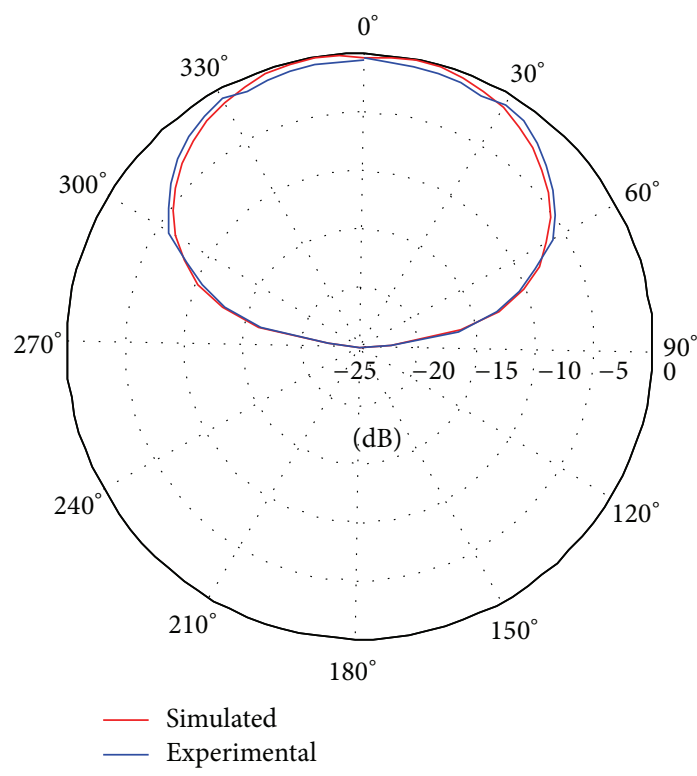

(a) $E_{\theta},\left(\phi=0^{\circ}\right)$ at $1.84 \mathrm{GHz}$

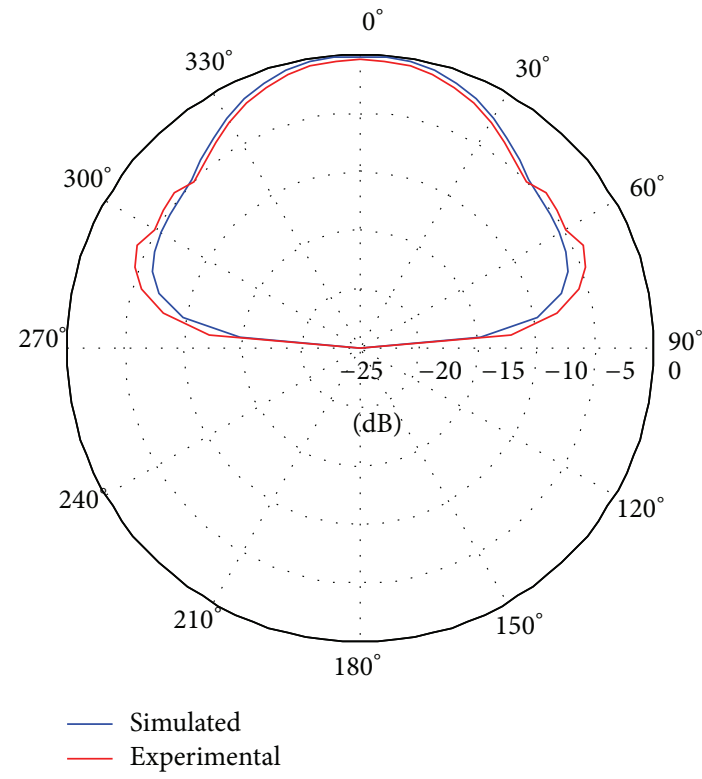

(b) $E_{\phi},\left(\phi=90^{\circ}\right)$ at $1.84 \mathrm{GHz}$

FIGURE 10: Comparative plot of simulated and measured radiated power versus angle of the proposed antenna.

TABLE 1: Design parameters of the proposed antenna.

\begin{tabular}{lc}
\hline Parameters & Value $(\mathrm{mm})$ \\
\hline$L$ & 120.0 \\
$W$ & 80.0 \\
$h$ & 9.0 \\
$L_{S}$ & 80.0 \\
$W_{S}$ & 8.0 \\
$L_{t}$ & 20.0 \\
$W_{t}$ & 37.0 \\
$L_{n}$ & 5.0 \\
$W_{n}$ & 7.0 \\
$L_{r}$ & 20.0 \\
$L_{P}, L_{q}$ & 52.0 \\
$W_{P}, W_{q}$ & 7.0 \\
$L_{g}$ & 16.0 \\
$L_{u}$ & 50.0 \\
$W_{u}$ & 50.0 \\
$\left(x_{0}, y_{0}\right)$ & $(13.5,-39.0)$ \\
\hline
\end{tabular}

antenna has a wide impedance bandwidth of $30.5 \%$ and creates a maximum radiation in broadside direction with $55^{\circ}$ beam width for E-plane and $45^{\circ}$ for $\mathrm{H}$-plane. The wide bandwidth is afforded by implementing an inclination at the upper portion of the patch. The effect of inclination angle is also calculated and it is found that at the angle of $30^{\circ}$, antenna characteristics are completely changed from broadband to dual band. The designed antenna also has a maximum gain of $9.86 \mathrm{dBi}$ and shows $74.5 \%$ efficiency. Hence, the appropriate position of the discontinuities strongly affects the antenna to achieve the broadband characteristics.

\section{Conflict of Interests}

The authors declare that there is no conflict of interests regarding the publication of this paper.

\section{References}

[1] R. Garg, P. Bhartia, and I. Bahl, Ittipiboon, Microstrip Antenna Design Handbook, Artech House, Norwood, Mass, USA, 2001.

[2] A. A. Deshmukh and G. Kumar, "Compact broadband Uslot-loaded rectangular microstrip antennas," Microwave and Optical Technology Letters, vol. 46, no. 6, pp. 556-559, 2005.

[3] A. A. Deshmukh and K. P. Ray, "Compact broadband slotted rectangular microstrip antenna," IEEE Antennas and Wireless Propagation Letters, vol. 8, pp. 1410-1413, 2009.

[4] A. A. Lotfi Neyestanak, F. Hojjat Kashani, and K. Barkeshli, "W-shaped enhanced-bandwidth patch antenna for wireless communication," Wireless Personal Communications, vol. 43, no. 4, pp. 1257-1265, 2007.

[5] F. Jolani, A. M. Dadgarpour, and H. R. Hassani, "Compact Mslot folded patch antenna for WLAN," Progress in Electromagnetics Research Letters, vol. 3, pp. 35-42, 2008.

[6] M. T. Islam, M. N. Shakib, and N. Misran, "Broadband E-H shaped microstrip patch antenna for wireless systems," Progress in Electromagnetics Research, vol. 98, pp. 163-173, 2009.

[7] M. S. Nishamol, V. P. Sarin, D. Tony, C. K. Aanandan, P. Mohanan, and K. Vasudevan, "A broadband microstrip antenna for IEEE802.11.A/WIMAX/HIPERLAN2 applications," Progress In Electromagnetics Research Letters, vol. 19, pp. 155-161, 2010.

[8] M. Abbaspour and H. R. Hassani, "Wideband star-shaped microstrip patch antenna," Progress in Electromagnetics Research Letters, vol. 1, pp. 61-68, 2008.

[9] S. Bhardwaj and Y. Rahmat-Samii, "A comparative study of cshaped, e-shaped, and u-slotted patch antennas," Microwave and Optical Technology Letters, vol. 54, no. 7, pp. 1746-1757, 2012. 
[10] X. L. Bao and M. J. Ammann, "Small patch/slot antenna with 53 input impedance bandwidth," Electronics Letters, vol. 43, no. 3, pp. 146-148, 2007.

[11] M. Albooyeh, N. Komjani, and M. Shobeyri, "A novel crossslot geometry to improve impedance bandwidth of microstrip antennas," Progress in Electromagnetics Research Letters, vol. 4, pp. 63-72, 2008.

[12] M. T. Islam, M. N. Shakib, and N. Misran, "Multi-slotted microstrip patch antenna for wireless communication," Progress In Electromagnetics Research Letters, vol. 10, pp. 11-18, 2009.

[13] P. Capece, L. Lucci, G. Pelosi, M. Porfilio, M. Righini, and W. Steffè, "A multilayer PCB dual-polarized radiating element for future SAR applications," IEEE Antennas and Wireless Propagation Letters, vol. 13, pp. 297-300, 2014.

[14] Zeland Software, IE3D Simulation Software, Version 14.05, Zeland Software, Fremont, Calif, USA, 2008. 

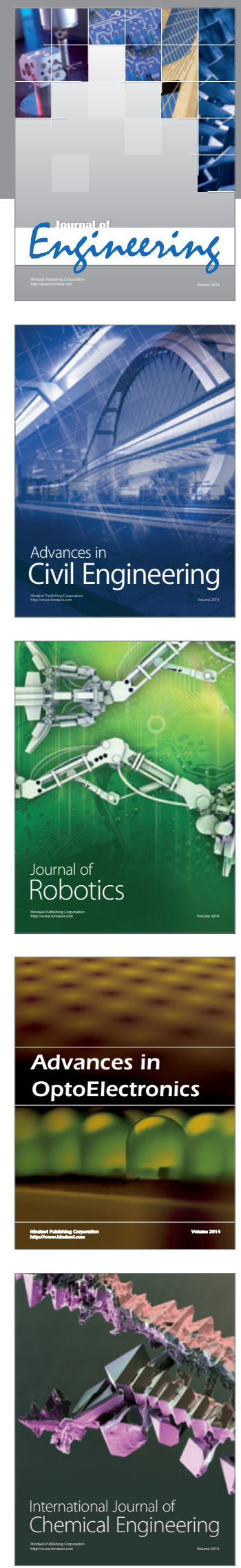

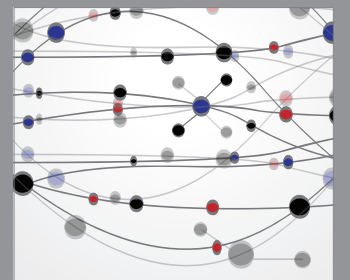

The Scientific World Journal
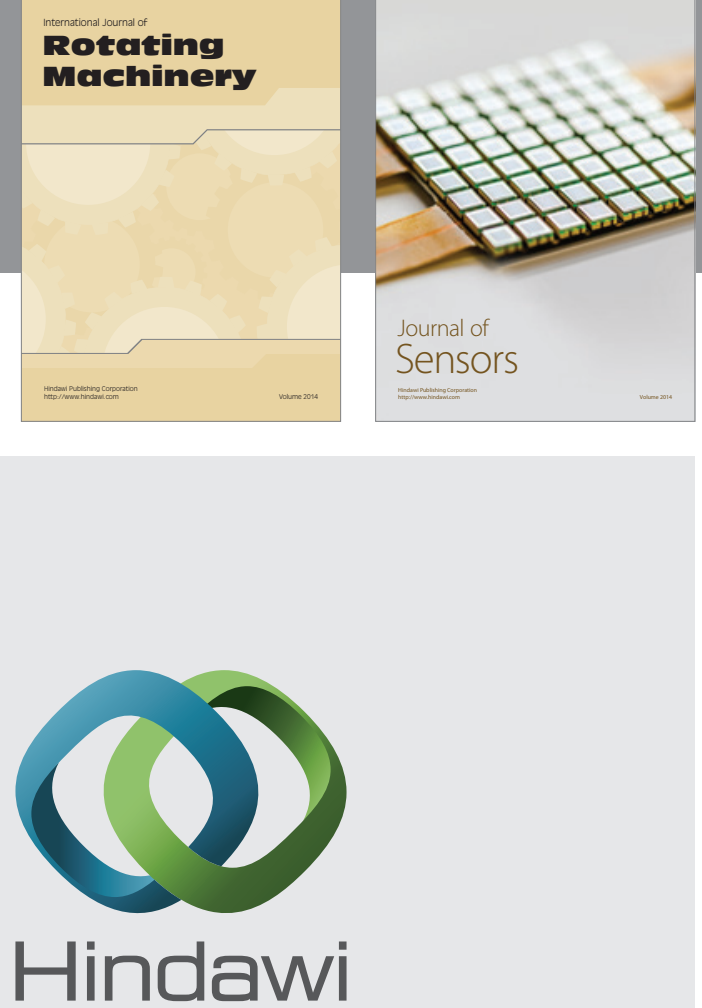

Submit your manuscripts at http://www.hindawi.com
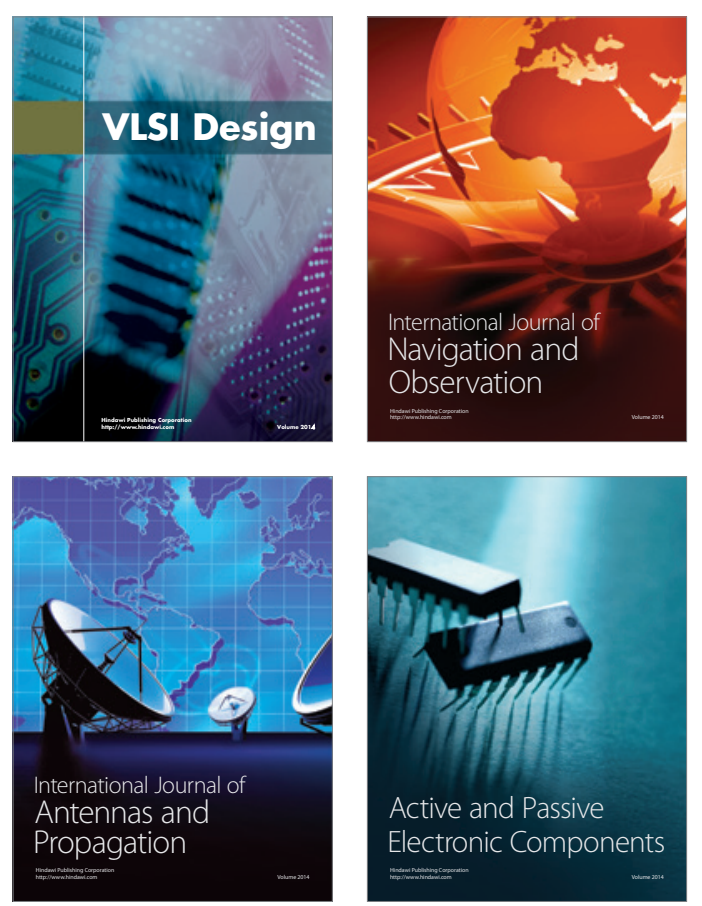
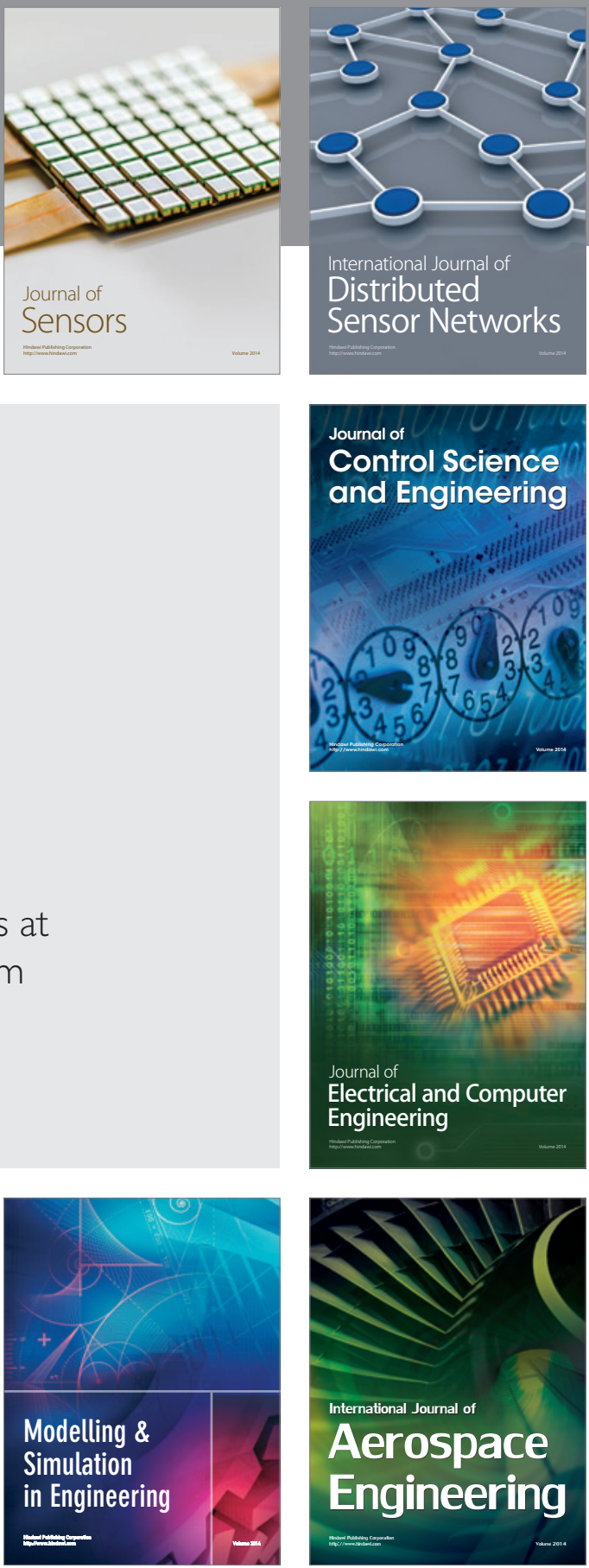

Journal of

Control Science

and Engineering
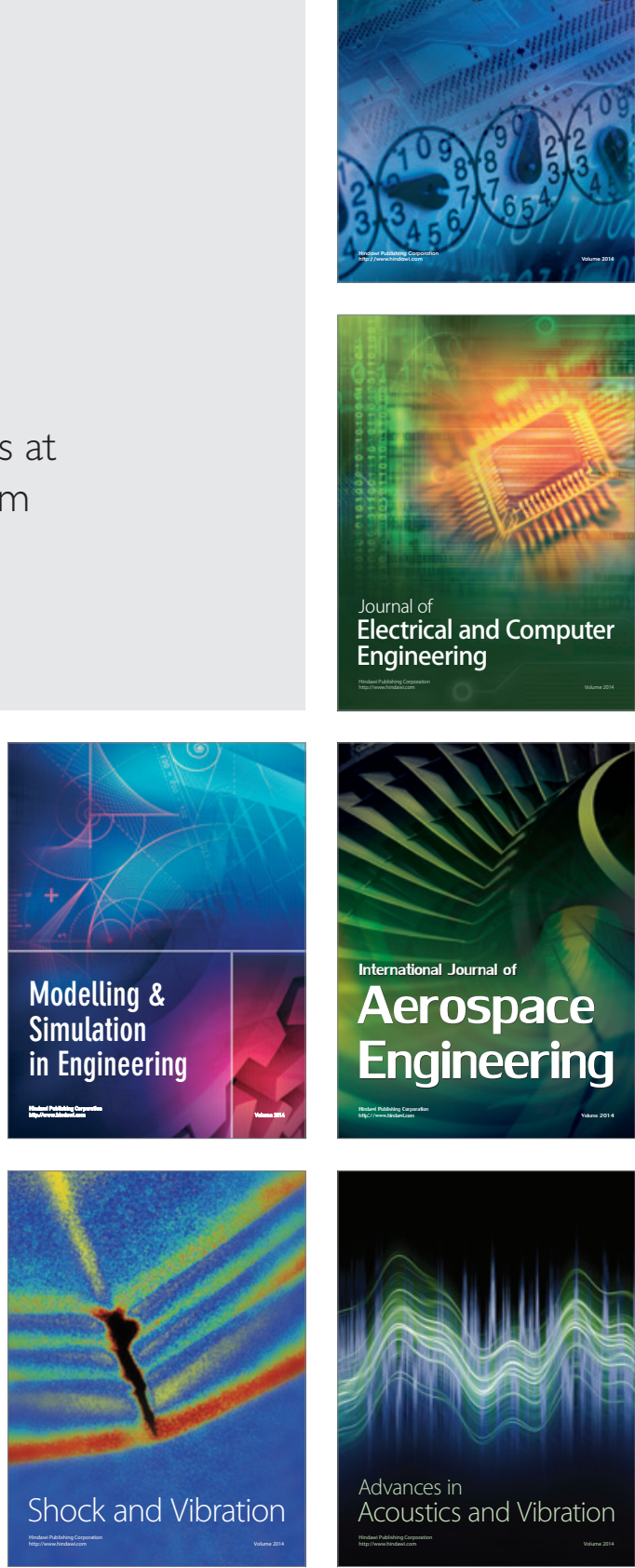